\title{
Stabbing Wire Technique as a Novel Conventional Initial Strategy for Percutaneous Coronary Intervention of Chronic Total Occlusion
}

\author{
Mohamed Mandour, Khaled Mandour* and Kareem Mandour \\ National Heart Institute, Egypt
}

Submission: February 10, 2017; Published: August 22, 2017

*Corresponding author: Khaled Mandour, National Heart Institute, Ibn El Nafes Sq-Cairo, Egypt, Tel: +201222253651;

Email:dr.khaledmandour@gmail.com

\section{Background}

CTOs can occur acutely and go unrecognized, as silent clinical events, but probably in more instances than not, they occur gradually over time. Often the area of the myocardium that is subtended by the totally occluded vessel is still very viable and functional despite having an occluded artery, because over time, collaterals have developed to keep the heart tissue alive. However, the collaterals have not been shown to supply enough blood and oxygen required when the demand of the heart muscle increases. Total re- vascularization and restoration of normal ante-grade flow can be very important for many patients with chronic total occlusion (CTO) and attributable symptoms, ischemia, and/or ventricular dysfunction/ dysrhythmia.

Technical success remains lower for CTO PCI than for PCI of non-CTO lesions and remains a major impediment to optimally managing patients with coronary CTO. Although overall СTO PCI success rates have been improved over recent years (approximately 90\%) reported at several experienced centers with focused CTO operators who have made changes in strategy and wire design with the help of new equipment designed specially for CTO PCI. Adherence to a procedural strategy that standardizes CTO technique and facilitates procedural success is recommended. Such a strategy would permit stepwise decisionmaking for ante-grade and retrograde methods; inform guide wire selection; and incorporate alternative approaches for instances of initial failure.

Using measures to minimize radiation exposure and contrast administration is recommended. CTO PCI is best performed at centers with dedicated CTO PCI experience and expertise.

\section{Introduction}

CTO procedures typically require greater resource, time and utilization, because of the greater complexity of having to cross the lesion first with a guide wire. The most common reason for failure of a CTO re-vascularization is an inability for the guide wire to successfully cross into the distal true lumen. The average total procedure time is typically about 2.5 hours. The number of guide wires, balloon angioplasty catheters, and stents that we use is typically greater than what we commonly use for a non-CTO PCI procedure. It has been previously suggested that CTO PCI was an economic deterrent, because of greater resource utilization.

We recently modified the CTO ante-grate strategy to overcome these limitation, time consumption and economic burden. In the present study, we describe a modified novel less cumbersome variant of the Penetrating wire technique, called "STABBING".

\section{Procedure Step}

a) Make one or two curves (depends on the anatomy) for the hydrophilic coating tapered (enabling it to engage in the small micro channels and navigate through to the distal true lumen. medium support wire, then direct it to the culprit artery, and reach the site of total occlusion.

b) If the total occlusion site has a stump or a nipple, insert the wire into the nipple.

c) If the total occlusion site shows a blunt end choose center of the occlusion in 2 perpendicular views and insert the wire to be locked inside the lesion.

d) If the total occlusion is at a bifurcation site then insert the wire to be wedged in between the two bifurcating vessels until you feel resistance.

e) Hold the wire firmly $2 \mathrm{~cm}$ outside the $\mathrm{Y}$ connector and then push the wire in the total occlusion like a stab or a pistol shot, and if fails u can straighten the distal end of the wire by $1.0 \mathrm{~mm}$ balloon or a micro catheter and then stab it again. 


\section{Aim of the Work}

To assess the impact of the new Stabbing wire technique as Conventional Initial Strategy on the outcomes of CTO intervention compared to standard CTO wire techniques.

\section{Patients and Methods}

From January to October 2015, a total of 92 patients were recruited from the Cath lab Unit and prospectively evaluated for the study endpoints. All patients with angiography showing chronic total occlusion, and prepared for СТО intervention were included in this study. Coronary angioplasty and re-vascularization achieved in all 92 patients.

These patients were divided into two groups: group A, comprising 46 patients (PCI done with Stabbing Wire Technique as Conventional Initial Strategy) and group B, comprising 46 patients (PCI done with standard techniques) (Figure 1).

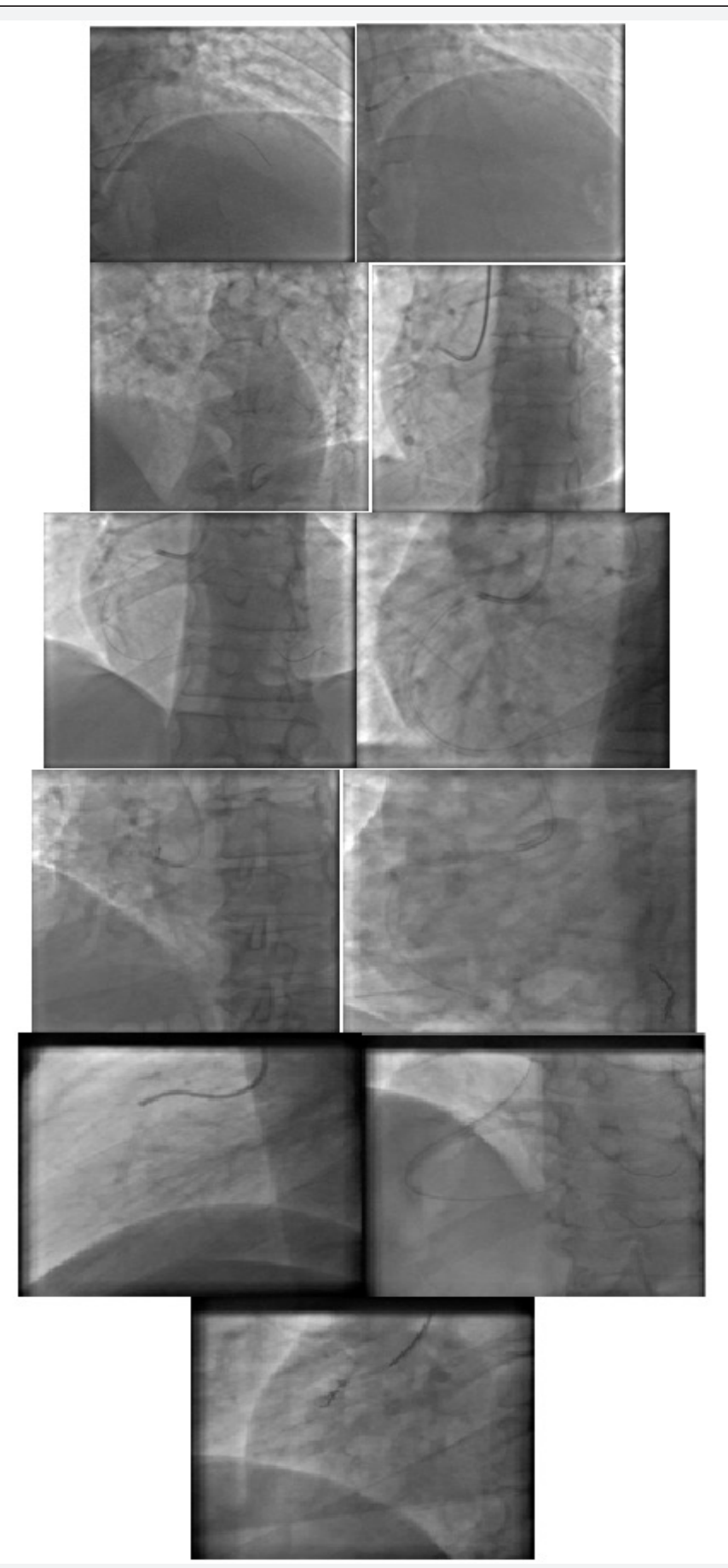

Figure 1: Patients ( $\mathrm{PCl}$ done with standard techniques). 


\section{Results}

There were no significant differences in terms of age, sex, and classical risk factors.

\section{Stabbing wire technique offered higher ante grade re- vascularization success rates}

The results of the current study revealed that Stabbing wire technique as Conventional Initial Strategy offered higher success rate of ante-grate CTO re-canalization and re- vascularization compared to the other wire techniques strategies.

Comparing the success rates of ante grate re-vascularization in both study groups, Stabbing wire technique as Conventional Initial Strategy had a significant higher success outcome with significant ( $p$-value 0.01).

\section{Stabbing wire technique and time consumption/ radiation dose}

The results of the current study revealed that Stabbing wire technique as Conventional Initial Strategy reduce time consumption therefore reduces radiation dose, compared to the other wire techniques strategies. Comparing the time consumption needed for CTO PCI in both study groups, Stabbing wire technique as Conventional Initial Strategy had a significant lower time consumption with significant (p-value 0.02).

\section{Stabbing wire technique and contrast use}

The results of the current study revealed that Stabbing wire technique as Conventional Initial Strategy reduce contrast use, compared to the other wire techniques strategies. Comparing the contrast use in both study groups, Stabbing wire technique as Conventional Initial Strategy had significant lower amounts of contrast used with significant (p- value 0.01).

\section{Stabbing wire technique and equipments use/ economic burden}

The results of the current study revealed that Stabbing wire technique as Conventional Initial Strategy reduce equipment usage therefore reduces economic burden, compared to the other wire techniques strategies. Comparing the economic burden in both study groups, Stabbing wire technique as Conventional Initial Strategy had a significant lower economic burden with significant (p-value 0.002).

\section{Conclusion}

This study describes the potential protective effects of the new stabbing wire technique in patients with CTO undergoing PCI with stenting. These findings may have implications for clinical trials investigating agents and equipment designed to reduce СТO PCI complications.

Because CTO PCI became relatively common and carries a lot more challenges and complications, it is imperative for patients with CTO to be identified in clinical trials.

This implies that modifying our techniques, upgrading our practice and education promoting should be emphasized in future, which may further shorten the time of CTO PCI and reduce the hazards it carries.

\section{Study Limitations}

This is a relatively small study, and the comparatively small number of patients in subgroups, considering the number of comparisons necessary, may influence the stability of the statistical estimates. It would also be interesting to determine whether the success of the new wire technique was more pronounced in different patient populations (i.e., LAD CTO vs. RCA CTO). However, further dividing our study population would result in such small subgroups that this would further jeopardize meaningful statistical comparisons. Therefore, larger studies are necessary to address these issues.

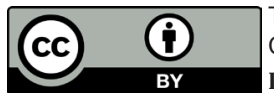

is work is licensed under Creative Commons Attribution 4.0 License

DOI: 10.19080/JOCCT.2017.07.555701

\section{Your next submission with Juniper Publishers} will reach you the below assets

- Quality Editorial service

- Swift Peer Review

- Reprints availability

- E-prints Service

- Manuscript Podcast for convenient understanding

- Global attainment for your research

- Manuscript accessibility in different formats

( Pdf, E-pub, Full Text, Audio)

- Unceasing customer service

Track the below URL for one-step submission https://juniperpublishers.com/online-submission.php 